\title{
Physiological effect of endobronchial radiotherapy in patients with major airway occlusion by carcinoma
}

\author{
J M Goldman, A S Bulman, A J Rathmell, B M Carey, M F Muers, C A F Joslin
}

\begin{abstract}
Background Endobronchial radiotherapy by a high dose rate remote afterloading technique (high dose rate brachytherapy) has become an established treatment for major airway occlusion by inoperable carcinoma of the bronchus. Only limited objective data on its effect on pulmonary physiology and on radiographic and bronchoscopic appearances are available. The aim of this study was to make a detailed assessment of patients before and after high dose rate brachytherapy to determine which investigations were useful and to generate data for comparing this with other methods of treatment.
\end{abstract}

Methods Twenty patients with major airway obstruction by inoperable lung cancer underwent a detailed assessment before receiving endobronchial radiotherapy (15 Gy at $1 \mathrm{~cm}$ in a single fraction) and six weeks after treatment. This included chest radiography, computed tomography of the thorax, bronchoscopy including an obstruction index, five minute walking tests, isotope ventilation and perfusion lung scanning, and full lung function tests with maximum inspiratory and expiratory flow-volume loops.

Results Nineteen patients (mean age 69 years) completed the study. Symptomatic improvement occurred in 17 patients. A collapsed lobe or lung, seen on the chest radiograph in 13, reexpanded in nine. Bronchoscopic appearances improved in 18 , the mean obstruction index decreasing from 6.2 to 2.8. The isotope scans showed significant increases in the percentage of total lung ventilation $(\dot{V})$ and perfusion (Q) measured over the abnormal lung $(V 17 \cdot 7 \%$ to $27 \cdot 7 \%$, Q $15 \cdot 1$ to $21 \cdot 9 \%$ ). Five minute walking distance (305 to $329 \mathrm{~m}$ ), forced expiratory volume in one second (FEV 1.45 to 1.61 1), forced vital capacity (FVC 2.17 to 2.48 1) and ratio of forced expiratory to forced inspiratory flow rate at $50 \%$ vital capacity $\left(\right.$ FEF $_{50} /$ FIF $_{50} 0.58$ to $0 \cdot 88)$ all increased significantly.

Conclusions Endobronchial radiotherapy led to subjective benefit in most cases in terms of symptoms and bronchoscopic and radiological appearances. There was objective improvement in spirometric indices and in exercise tolerance with increased pulmonary ventilation and perfusion and evidence of decreased intrathoracic airway obstruction.

\section{(Thorax 1993;48:110-114)}

The concept of brachytherapy for carcinoma of the bronchus is not new. Radon seeds were implanted via the rigid bronchoscope as long ago as $1921 .^{1}$ The development of high dose rate remote afterloading techniques using iridium-192 has brought endobronchial radiotherapy back to prominence. ${ }^{23}$ Despite extensive use of this technique in three continents there are only limited objective data regarding its effect on physiological, radiological, and bronchoscopic indices. We therefore embarked on a detailed study of the effect of high dose rate endobronchial radiotherapy in 20 patients with major airway occlusion by carcinoma. Our aim was to provide objective information on the effect of this technique that would allow it to be compared with other forms of treatment, such as laser resection, cryotherapy, and external beam radiotherapy.

\section{Methods}

We studied 20 patients with major airway occlusion by histologically proved carcinoma of the bronchus. Criteria for entry into the study were: inoperable tumour with no potential for cure by radical radiotherapy; World Health Organisation performance status $0-2$; patient judged to be clinically fit for the procedure and expected to have at least three months' survival; bronchoscopic appearance of a predominantly endobronchial tumour that could be bypassed by a $2 \mathrm{~mm}$ plastic catheter; previous diagnostic bronchoscopy well tolerated; no indication for urgent radiotherapy or laser resection; no indication for chemotherapy. Patients who had previously received external beam radiotherapy up to maximum cord tolerance were included, as was one patient with small cell lung cancer who had relapsed after two different chemotherapy regimens.

Patients underwent pretreatment assessment that included scoring of symptoms, chest radiography, computed tomography of the thorax, isotope ventilation and perfusion lung scanning, full lung function tests (including flow-volume loops), and a series of five minute walking tests. Dyspnoea, haemoptysis, cough, pain, weight loss, and general wellbeing were assessed as "none," 
"mild," "moderate," or "severe."

Computed tomography was performed with a Somatom DRH scanner. Contiguous 8 $\mathrm{mm}$ sections were obtained through the lungs from the thoracic inlet to the diaphragm during infusion of intravenous contrast (Iopamidol $370 \mathrm{mg} / \mathrm{ml}$; E Merck Ltd). All scans were reviewed on both soft tissue and lung windows. Where possible tumour volume was measured and an assessment of major airway patency was made.

Isotope scanning was performed with technetium-99m labelled macroaggregated albumin to measure perfusion and with krypton-81m gas to measure ventilation. Images were acquired by a gamma camera with the patient in a seated position. Posterior and anterior images were recorded on a computer and regions of interest drawn around each lung. The differential function for each lung was then calculated and these data were expressed as percentages of total counts detected in the normal and abnormal lung.

The lung function tests we performed were spirometry, lung volumes, and total lung capacity measured by helium dilution with a modified Collins water filled spirometer. Total lung capacity was measured by plethysmography (Gould Autobox 2800) and transfer factor by the carbon monoxide single breath method (PK Morgan carbon monoxide analyser); specific airways resistance and maximum inspiratory and expiratory flowvolume loops were determined by means of the body plethysmograph. Five minute walking tests were performed in a level corridor under standardised conditions of supervision and encouragement. Five tests were performed at each assessment, to allow for any training effect, ${ }^{4}$ and the furthest distance walked was used for analysis.

After the pretreatment assessment fibreoptic bronchoscopy was performed (by JMG) under local anaesthesia and light sedation (atropine $0.6 \mathrm{mg}$ and midazolam $2-5 \mathrm{mg}$ ) with an Olympus $1 \mathrm{~T}$ fibrescope. The degree of major airway obstruction was estimated in terms of a bronchial obstruction index (a semi-quantitative method that allocates a score based on the degree of major airway obstruction and weighted according to the site of the tumour (table 1$).^{5}$ A $1.9 \mathrm{~mm}$ flexible applicator tube (Nucletron) and guidewire twice its length were then inserted through the biopsy channel of the bronchoscope and passed distal to the tumour under fluoroscopic screening. The bronchoscope and then the guidewire were removed and the

Table 1 Major airway obstruction scoring method ${ }^{5 \star}$

\begin{tabular}{lrll}
\hline & \multicolumn{3}{l}{$\%$ obstruction } \\
\cline { 2 - 4 } & $>50$ & $10-50$ & $<10$ \\
\hline Trachea & 10 & 5 & 2 \\
Mainstem bronchi & 6 & 3 & 1 \\
Lobar bronchi & 2 & 1 & 0
\end{tabular}

*Points are scored for the degree of obstruction at each site as assessed at bronchoscopy; atelectasis or pneumonia receives an additional two points per lobe. latter was replaced with a marker wire with 1 $\mathrm{cm}$ graduations to allow accurate planning of the radiotherapy field. The applicator was taped at the nose and a chest radiograph taken to confirm its position. The volume of tissue treated extended $2 \mathrm{~cm}$ proximal and 2 $\mathrm{cm}$ distal to the tumour. The applicator was connected to a high dose rate Microselectron (Nucletron), which advanced a high activity $1.1 \mathrm{~mm}$ iridium-192 source along the treatment field under remote control. An absorbed radiation dose of $15 \mathrm{~Gy}$ was delivered to the target volume $1 \mathrm{~cm}$ from the source axis. The whole procedure took $30-40$ minutes with 10-15 minutes of radiation exposure.

Six weeks after treatment patients had a post-treatment assessment identical to the pretreatment tests and including a further fibreoptic bronchoscopy. Pretreatment and post-treatment indices were compared. Symptoms were assessed as better, the same, or worse. Chest radiographs were examined for re-expansion of collapsed lobes and changes in the size of any mass. Computed tomograms were analysed in a similar manner, with emphasis on change in volume of any mass lesion. Bronchoscopic appearances were compared in terms of appearance and obstruction score. Ventilation and perfusion lung scans, five minute walking distance, pulmonary function tests and measurements derived from flow-volume loops were compared by means of Student's paired $t$ test. Bronchoscopic obstruction scores were compared with a Wilcoxon rank sum test. Results are presented as means with standard deviations in parentheses.

\section{Results}

Seventeen men and three women (mean age 69 (range 49-80) years) entered the study. One patient, a 74 year old woman with squamous cell carcinoma, failed to complete the protocol because she found the assessment too arduous. Fifteen patients completing the study had a diagnosis of squamous cell carcinoma, three large cell carcinoma, and one small cell carcinoma. Four patients had had previous radiotherapy, one previous surgery, one previous laser therapy, and one (the patient with small cell lung cancer) previous chemotherapy. Treatment was well tolerated in every case and the mean volume of the tissue treated was 10 (range 6-12) $\mathrm{cm}^{3}$.

Symptomatic improvement was obtained

Table 2 Effect of endobronchial radiotherapy on symptoms and radiographic appearances six weeks after treatment in patients with major airway occlusion by carcinoma of the bronchus

\begin{tabular}{lrccl}
\hline & Total & Better & Same & Worse \\
\hline Dyspnoea & 19 & 17 & 2 & 0 \\
Haemoptysis & 6 & 6 & 0 & 0 \\
Cough & 19 & 7 & 10 & 2 \\
Collapse & 13 & 9 & 3 & 1 \\
Masst & 6 & 2 & 1 & 3 \\
\hline
\end{tabular}

*On radiograph

tOn computed tomogram or radiograph. 
Figure 1 Anatomical location of endobronchial tumour in the 19 patients studied.

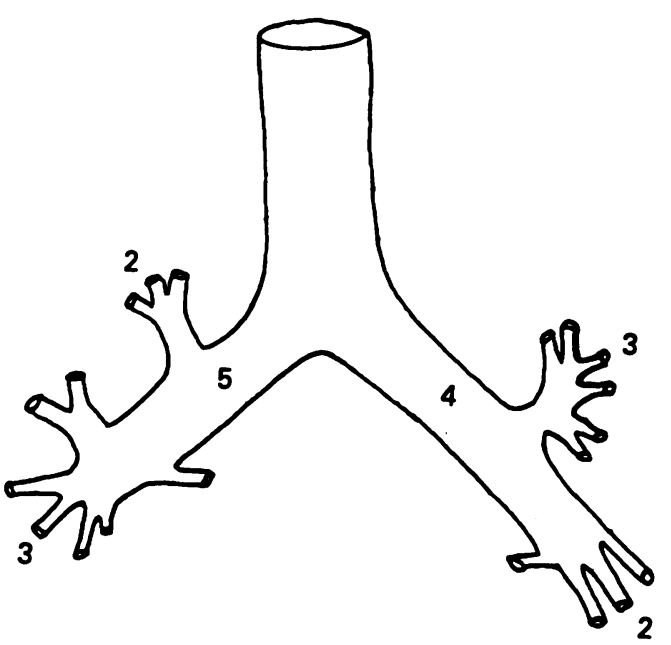

in 17 patients; one felt no different and one felt worse (table 2). Relief of dyspnoea and haemoptysis was notably more frequent than relief of cough.

The chest radiograph showed collapse of a lobe or lung in 13 patients (right upper lobe in three, right lower lobe in two, left upper lobe in five, left lower lobe in two, and left lung in one), a mass in five, and a normal film in one. The post-treatment radiograph showed substantial re-expansion in the one patient with a complete lung collapse and in eight patients with lobar collapse. One patient with a mass showed improvement (table 2).

It was not usually possible to make accurate estimates of tumour volume to assess the effects of treatment because tumour could not be reliably separated from adjacent collapsed or consolidated lung on the computed tomogram. In one patient with a normal chest radiograph the computed tomogram showed a mass that subsequently diminished after treatment.

The sites of major airway occlusion by tumour are shown in figure 1. Bronchoscopic appearances were consistently improved after endobronchial radiotherapy. Eight patients had complete clearing of tumour from the bronchial tree, nine had partial clearing, and two had unchanged appearances. There was a significant improvement in the mean obstruction index after treatment from $6.2(2.0)$ to $2 \cdot 8(2 \cdot 1)$, range $0-8 ; p<0.001)$. Only two patients failed to achieve an improved score.

There was a significant increase in fractional ventilation and perfusion scores for the abnormal lung after treatment (fig 2). Ventilation rose from $17.0 \%(15.2 \%)$ of the isotope count to $27 \cdot 7 \%(14 \cdot 1 \%)$; $(p<0.005)$, a $63 \%$ improvement, and perfusion from $15 \cdot 1 \%(12 \cdot 7 \%)$ to $21.9 \%(13.4 \%)$; ( $p<$ 0.005 ), a $45 \%$ improvement. The mean five minute walking distance (figure $3 \mathrm{~A}$ ) increased by $7 \%$ from $305(80)$ to 329 (67) $\mathrm{m}$ (p < 0.01 ).

Forced expiratory volume in one second $\left(F_{1} V_{1}\right)$ and forced vital capacity (FVC) improved significantly whether expressed as absolute volumes or percentages of normal predicted values ${ }^{6}$ (table 3, figure 4). There was no such effect on measures of lung volume or gas transfer. The flow-volume loops showed a significant increase in the ratio of forced expiratory flow rate to forced inspiratory flow rate at $50 \%$ vital capacity $\left(\mathrm{FEF}_{50} / \mathrm{FIF}_{50}\right)$ (fig 3B), consistent with a decrease in intrathoracic airway obstruction. ${ }^{7}$

Patients with tumour occluding a main bronchus had a greater improvement in
Figure 2 Isotope ventilation and perfusion scans before and after endobronchial radiotherapy. Ventilation and perfusion are expressed as the percentage of counts over the abnormal lung.

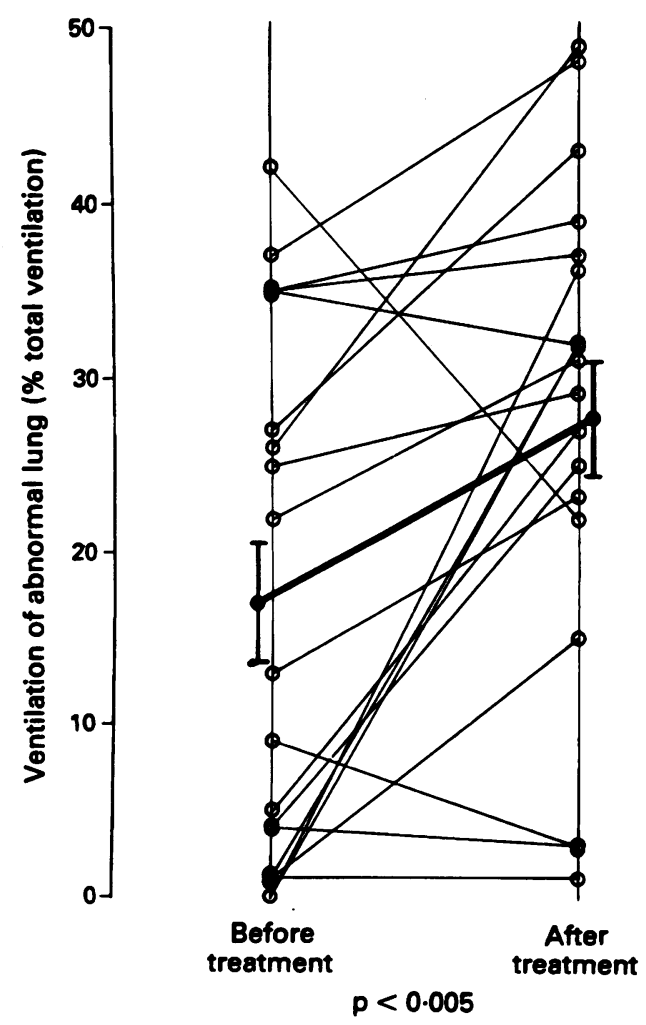

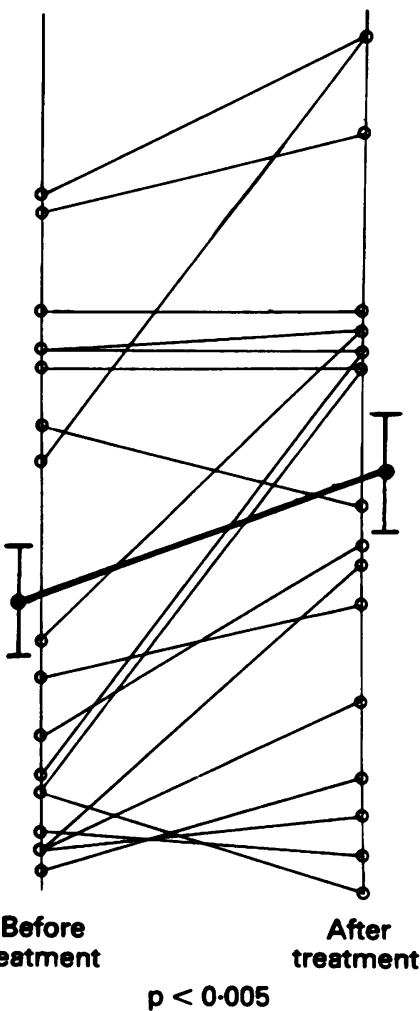


Figure 3 Five minute walking distance and the ratio of forced expiratory to inspiratory flow at $50 \%$ vital capacity $\left(F E F_{50} / F I F_{50}\right)$ before and after endobronchial radiotherapy.

Figure 4 Forced expiratory volume in one second $\left(F E V_{1}\right)$ and forced vital capacity (FVC) before and after endobronchial radiotherapy.

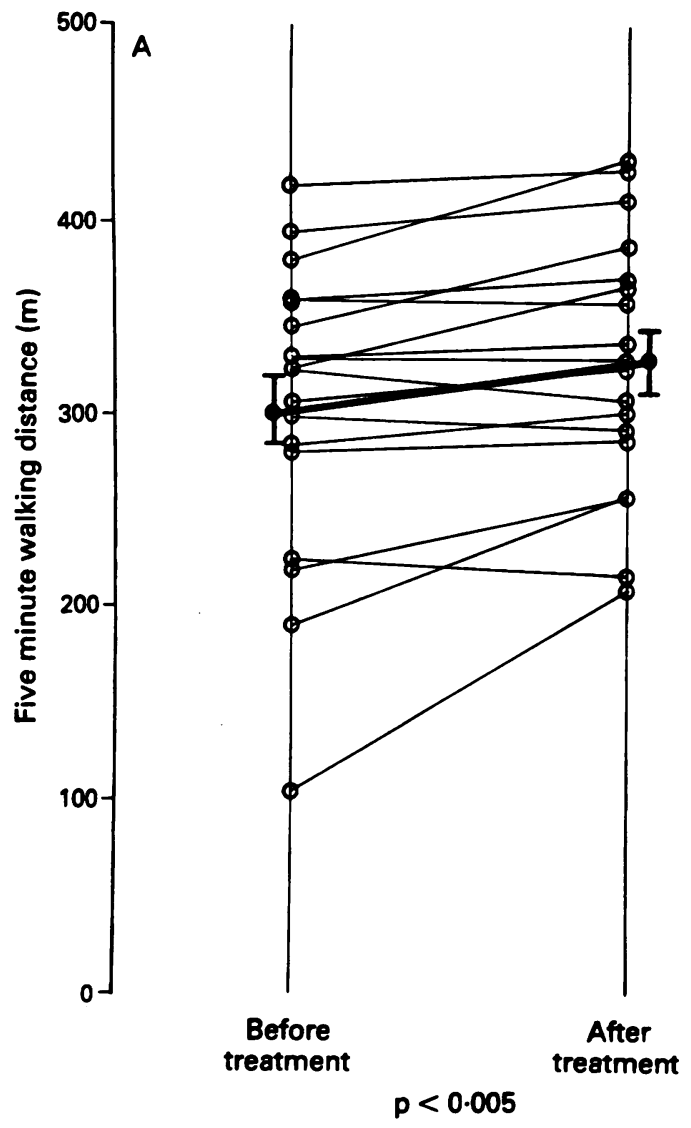

physiological indices than those who had tumour in a lobar bronchus; this was true for spirometric indices, $\mathrm{FEF}_{50} / \mathrm{FIF}_{50}$ ratio, fractional ventilation and perfusion scores, and five minute walking distance. When their data were analysed alone patients with obstruction
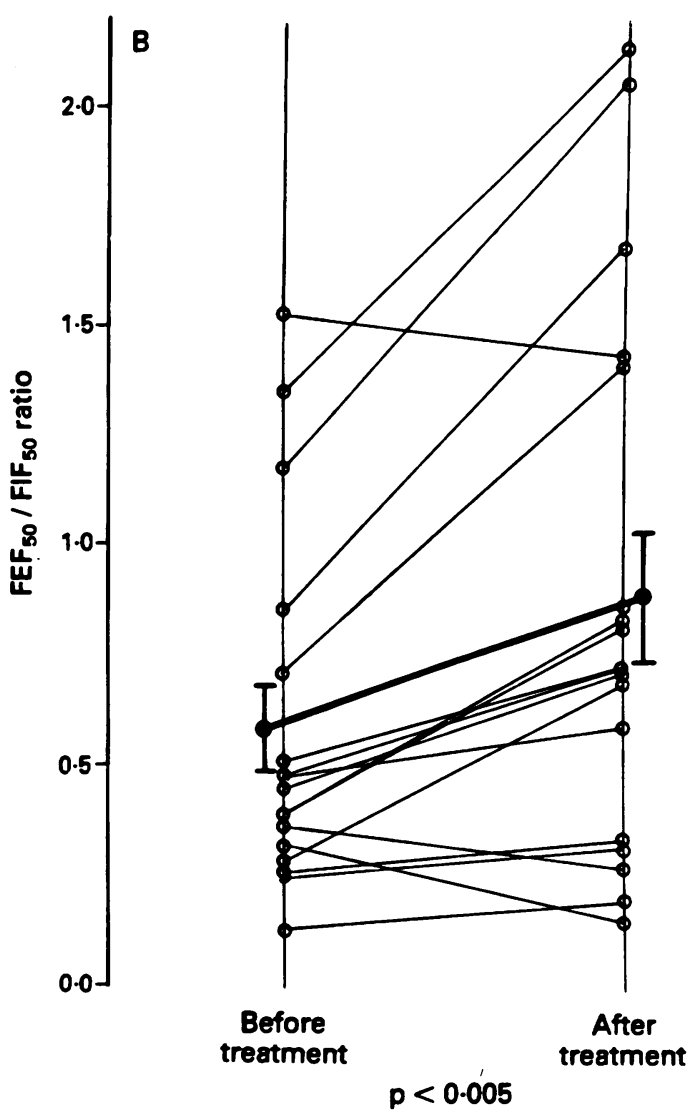

of a lobar bronchus did not have a statistically significant improvement in these objective measurements.

All patients survived six weeks, including the patient who did not complete the second assessment. There were no serious complica-

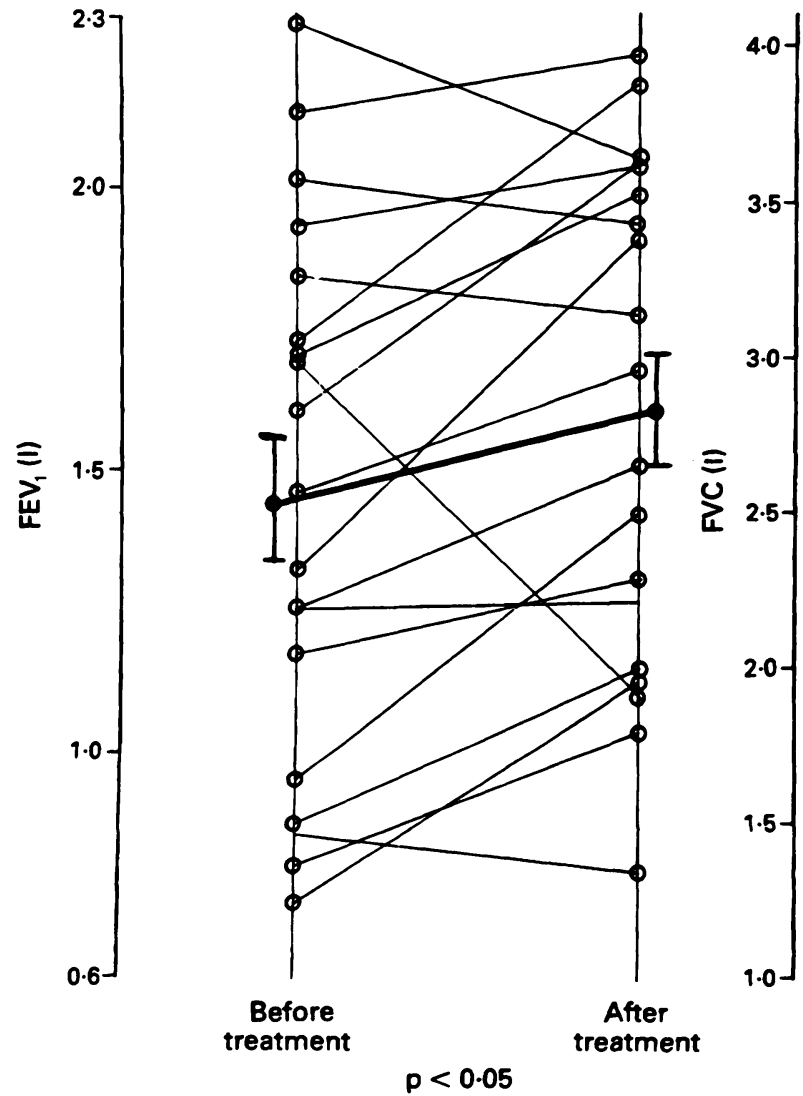


Table 3 Effect of endobronchial radiotherapy on lung function in patients with major airway occlusion by carcinoma of the bronchus: mean (SD) values of lung function indices before and after treatment

\begin{tabular}{|c|c|c|c|}
\hline & Before & After & $p$ \\
\hline $\mathrm{FEV}_{1}(\mathrm{l})$ & $1.45(0.48)$ & $1.61(0.45)$ & $<0.05$ \\
\hline $\mathrm{FEV}_{1}(\%)$ & $55 \cdot 5(16 \cdot 5)$ & $62 \cdot 3(17 \cdot 5)$ & $<0.05$ \\
\hline FVC (1) & $2 \cdot 17(0.72)$ & $2 \cdot 48(0.59)$ & $<0.005$ \\
\hline FVC (\%) & $63.9(16.9)$ & $74.0(14 \cdot 8)$ & $<0.005$ \\
\hline $\mathrm{FEF}_{50} / \mathrm{FIF}_{50}$ & $0.58(0.41)$ & $0.88(0.63)$ & $<0.005$ \\
\hline TLC box (1) & $5.89(1 \cdot 12)$ & $6.04(1.03)$ & NS \\
\hline TLC helium (1) & $4.86(1.05)$ & $5.10(0.99)$ & NS \\
\hline FRC (1) & $3.98(0.80)$ & $4 \cdot 17(0.83)$ & NS \\
\hline RV (l) & $3.23(0.84)$ & $3 \cdot 15(0.77)$ & NS \\
\hline sGaw $(1 / \mathrm{kPa} / \mathrm{s})$ & $1 \cdot 16(0.55)$ & $1 \cdot 12(0.46)$ & NS \\
\hline TLCO $(\mathrm{mmol} / \mathrm{min} / \mathrm{kPa})$ & $3.88(1.44)$ & $3 \cdot 80(1 \cdot 72)$ & NS \\
\hline $\mathrm{KCO}(\mathrm{mmol} / \mathrm{kPa} / \mathrm{min} / \mathrm{l})$ & $0.81(0.33)$ & $0.72(0.34)$ & NS \\
\hline
\end{tabular}

FEV - forced expiratory volume in one second; FVC - forced vital capacity; $\mathrm{FEF}_{50} / \mathrm{FIF}_{50}$-ratio of forced expiratory to inspiratory flow at $50 \%$ of vital capacity; TLC-total lung capacity; FRC-functional residual capacity; RV-residual volume; sGaw-specific airways resistance; TLCO-carbon monoxide transfer factor; KCO-transfer coefficient (TLCO corrected for alveolar volume). was a significant increase in ventilation without a significant change in perfusion in only one subject. Symptomatically the patient did not deteriorate, though there was no improvement in symptoms or five minute walking distance.

We have used the five minute walking distance as an objective measure of exercise tolerance. ${ }^{4}$ The significant improvement we observed has not previously been reported after endobronchial radiotherapy. The greatest improvement was in patients with obstruction of a main bronchus (292-331 m).

After endobronchial radiotherapy there were small but significant improvements in $\mathrm{FEV}_{1}$ and FVC (table 3). Other lung function indices did not alter significantly, with the exception of $\mathrm{FEF}_{50} / \mathrm{FIF}_{50}$ ratio, which increased as would be expected with a reduction in intrathoracic endobronchial tumour. ${ }^{7}$ These improvements were present predominantly in those with obstruction of a major bronchus (rather than a lobar bronchus) and it is these patients who should derive maximal benefit from the technique.

Our study has provided detailed objective data that show the effectiveness of high dose rate brachytherapy in treating patients with major airway occlusion by carcinoma of the bronchus. The results have allowed us to define the measurements likely to be of most use for comparing different treatment regimens. We conclude that patients can be fully assessed with a simple evaluation of symptoms, chest radiography, repeat bronchoscopy, and the relatively simple physiological techniques of timed walking tests, spirometry, and flow-volume loops. When available ventilation and perfusion lung scanning may also be useful.

We wish to thank the staff of the lung function and physiotherapy departments at Killingbeck Hospital, the operating theatre and computed tomography scanning unit at Cookridge Hospital, and the department of nuclear medicine at St James's Hospital. Special thanks go to Elaine Power for administrative help and to the Killingbeck chest research fund for financial support.

1 Yankauer S. Two cases of lung tumour treated bronchoscopically. NY Med f 1922;115:741-2.

2 Nori D, Hilaris B, Martini N. Intraluminal irradiation in bronchogenic carcinoma. Surg Clin N Am 1987;67: 1093-102.

3 Macha HN, Coch K, Stadler M, Schumacher W, Krumahaar ED. New technique for treating occlusive and stenotic tumours of trachea and main bronchi: endobronchial irradiation by high dose iridium-192 combined with laser canalisation. Thorax 1987;42: 511-5.

4 Knox AJ, Morrison JFJ, Muers MF. Reproducibility of walking tests in chronic obstructive airways disease. walking tests in chronic

5 Speiser B, Spratling L. Intermediate dose rate remote afterloading brachytherapy for intraluminal control of bronchogenic carcinoma. Int $\mathcal{f}$ Radiat Oncol Biol Phys 1990:18:1443-8.

6 Quanjer $\mathrm{PhH}$, ed. Standardised lung function testing. Report of working party of the European Community for coal and steel. Bull Eur Physiopathol Respir 1983;19 for coal and

Harrison BDW. Upper airway obstruction-a report on 16 patients. $Q \mathcal{F}$ Med 1976;45:625-32.

8 Stout R, Burt PA, Barber PV, O'Driscoll BR, Notley HM. HDR brachytherapy for palliation and cure in bronchial carcinoma: the Manchester experience using a single dose technique. Selectron Brachytherapy fournal 1990; suppl:48-53. monary vasculature) could increase the physiological dead space and lead to a deterioration in breathlessness. In our study there 